\title{
Gynecological surgical practice during the 2020 COVID-19 pandemic
}

\author{
Maria Alexandra CIOCARLAN ${ }^{1}$, Corina GICA $^{1}$, Anca Maria PANAITESCU ${ }^{1,2}$, Iulia HULUTA ${ }^{1}$, \\ Gheorghe PELTECU ${ }^{1,2}$, Radu BOTEZATU ${ }^{1,2}$, Nicolae GICA ${ }^{1,2}$ \\ ${ }^{1}$ Filantropia Clinical Hospital, Bucharest, Romania \\ 2 "Carol Davila" University of Medicine and Pharmacy, Bucharest, Romania
}

In the past year, the SARS-CoV-2 pandemic had a great impact on surgical services worldwide. The effects of the two phases of the pandemic are reflected in decreasing elective procedures, especially those addressed to benign diseases. During those times, a high rate of rescheduled, postponed, or canceled interventions was recorded [1]. This may have been caused by various factors, including the restrictions imposed by the authorities, the fear of contracting the infection, or the reduced number of consultants available [2].

Another significant vector that played an important role in maintaining and spreading the pandemic, and therefore in destabilizing even more the surgical activity, was the asymptomatic patient. In a surgical setting, an asymptomatic COVID-19 patient may potentially expose health care providers to virus-contaminated aerosol through surgical and anesthetic procedures, transmit the disease to other hospitalized patients and trigger in-hospital outbreaks [3]. This led to a better preoperative screening, in attempt to detect those patients and protect medical staff and other patients from getting the virus [4].

Being a disease associated with high morbidity and mortality rates, especially after surgery [3], SARS-CoV-2 infection in patients with surgical pathologies forced to a different approach, based on a non-operative management [1]. This was particularly possible for the non-oncological diseases [5], that did not affect significantly patient's quality of life, and for asymptomatic
SARS-CoV-2 patients [3], and in most cases, it was a matter of temporizing the surgical approach.

On a lower scale, analyzing the surgical activity within Filantropia Clinical Hospital in Bucharest during the SARS-CoV-2 pandemic gives us important information, that matches the global changes. Making a comparison between 2019 and 2020 regarding the overall number of surgical interventions (including laparotomies, laparoscopies, oncologic and non-oncologic procedures), we see a decrease of $18 \%$ in 2020 (Figure 1). The number of laparoscopies in 2020 was reduced with $14 \%$, and the number of laparotomies with $19 \%$, compared to 2019. As we stated before, there was a decrease in elective non-oncological procedures, with up to $22 \%$ (Figure 2), while oncologic procedures suffered only a $4 \%$ drop (Figure 3 ).

Another important aspect of COVID-19 pandemic was the high number of rescheduled and postponed procedures, which reached a pitch during March and April 2020. In March, out of a total of 156 surgical procedures, 30 were postponed and 4 rescheduled, while in April there was only a total of 49 interventions, out of which 17 were postponed and 1 rescheduled.

During the second wave of the pandemic, in November, despite the raising number of personnel getting infected and hospital being temporary closed for health security reasons, we managed to maintain a quasi-normal surgical activity, with only 14 procedures postponed and 1 rescheduled, out of a total of 126 (Figure 4). 


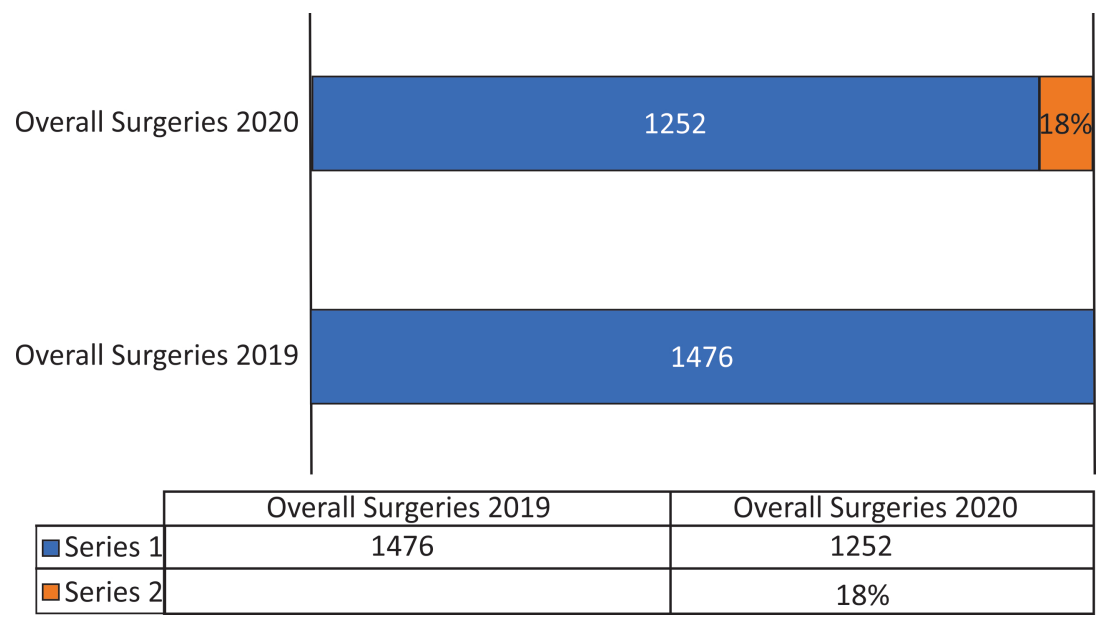

FIGURE 1. Comparison between 2019 and 2020 regarding the overall number of surgical interventions

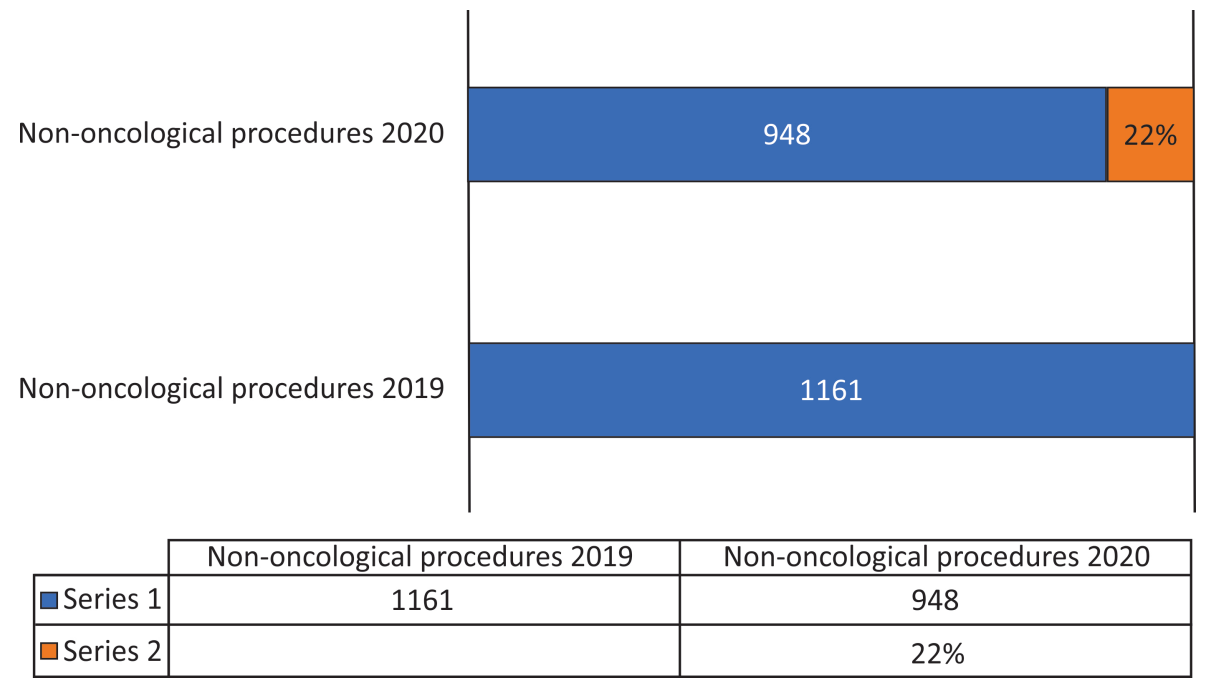

FIGURE 2. Comparison between 2019 and 2020 regarding the number of non-oncological procedures

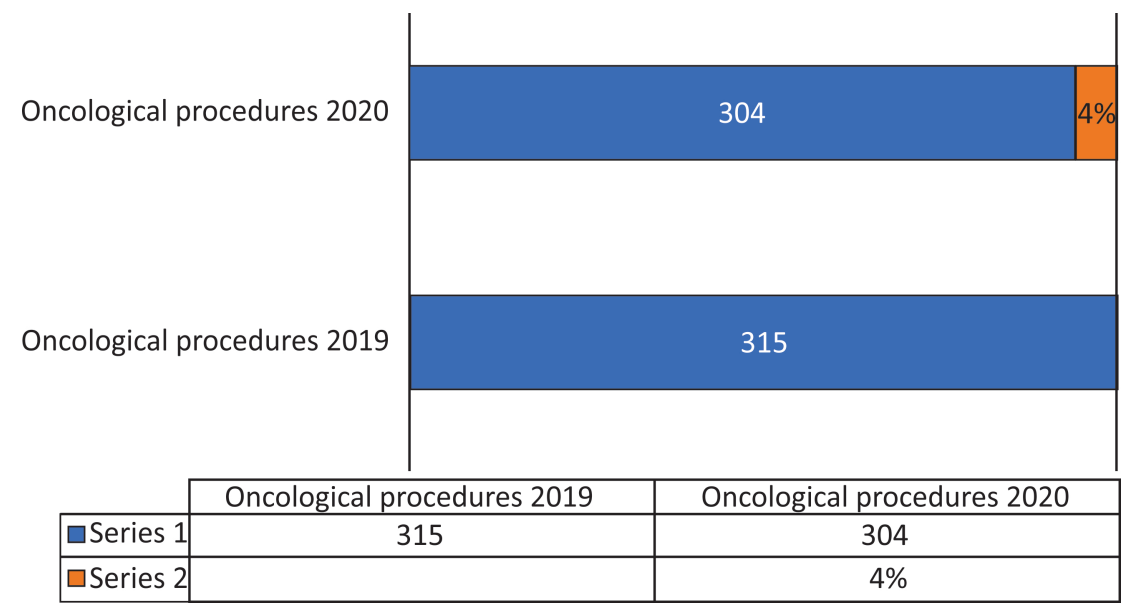

FIGURE 3. Comparison between 2019 and 2020 regarding the number of oncological procedures 


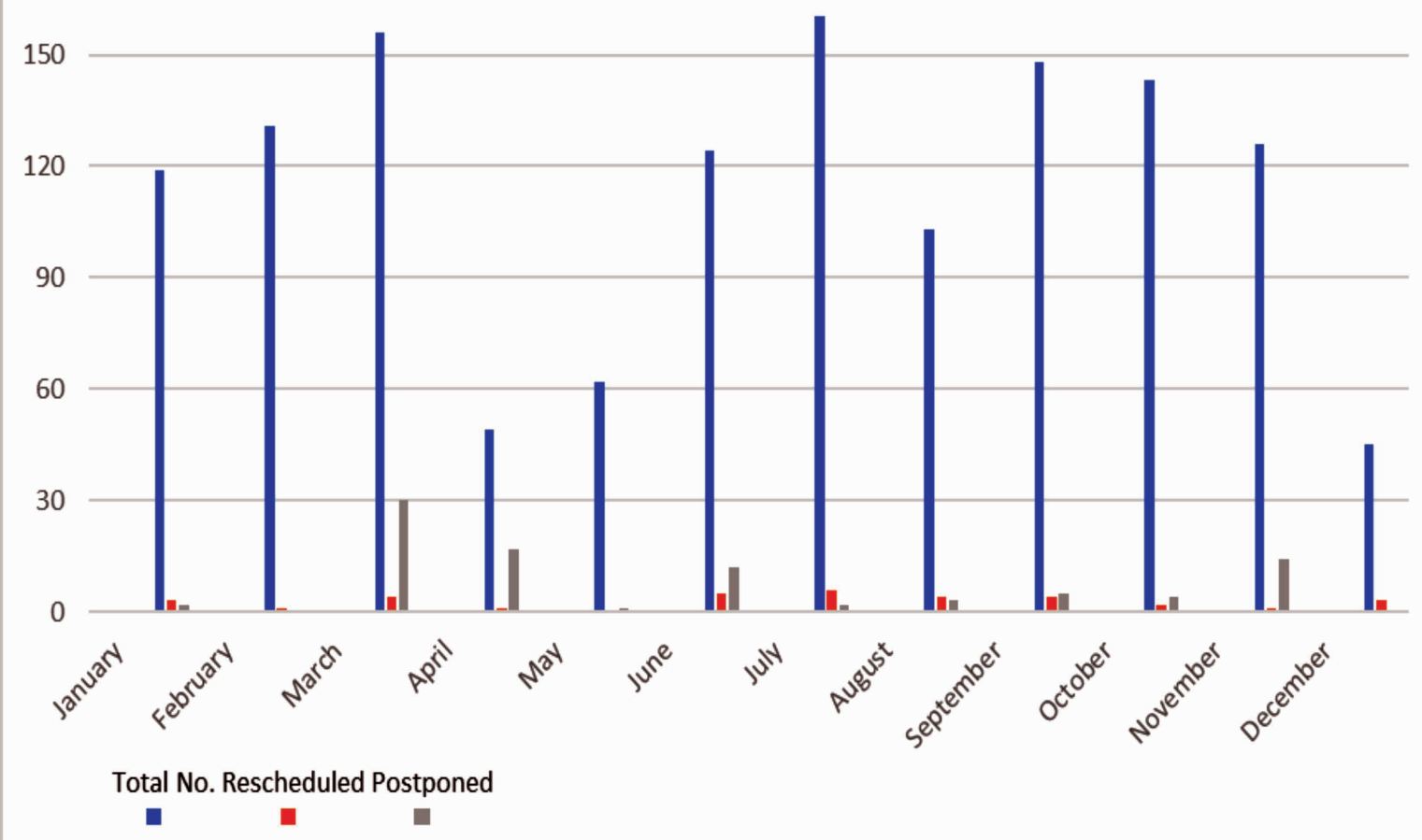

FIGURE 4. Evolution of rescheduled and postponed surgical procedures during COVID-19 pandemic

This data gives us an overview of the pandemic effects on the surgical activity in a non-COVID hospital. COVID-19 pandemic disrupted the normal surgical practices due to workforce shortages, high number of infections among population, as well as resource limitation [5]. This led to a tendency to adapt surgical and health strategies to face the SARS-CoV-2 pandemic, including a better preoperative screening, using dedicat- ed Personal Protective Equipment (PPE) and temporary non-operative management in suitable cases $[1,3]$. With increasing relaxation measures taken worldwide, we must remain conscious of the threat that COVID-19 pandemic represented for surgical services, and maintain a preventive attitude, in order to keep carrying out our activity.

Conflict of interest: none declared Financial support: none declared

\section{REFERENCES}

1. Ielpo B, Podda M, Pellino G, Pata F, Caruso R, Gravante G, Di Saverio S; ACIE Appy Study Collaborative. Global attitudes in the management of acute appendicitis during COVID-19 pandemic: ACIE Appy Study. Br J Surg. 2020 Oct 8:10.1002/bjs.11999.

2. An Y, Bellato V, Konishi T, Pellino G, Sensi B, Siragusa L, Franceschilli M, Sica GS; S-COVID Collaborative Group. Surgeons' fear of getting infected by COVID19: A global survey. Br J Surg. 2020 Oct;107(11):e543-e544.
3. Bellato V, Konishi T, Pellino G, An Y, Piciocchi A, Sensi B, Siragusa L, Khanna K, Pirozzi BM, Franceschilli M, Campanelli M, Efetov S, Sica GS; S-COVID Collaborative Group. Screening policies, preventive measures and in-hospital infection of COVID-19 in global surgical practices. J Glob Health. 2020 Dec;10(2):020507.

4. Bellato V, Konishi T, Pellino G, An Y, Piciocchi A, Sensi B, Siragusa L, Khanna K, Pirozzi BM, Franceschilli M, Campanelli M, Efetov S, Sica GS; S-COVID Collaborative
Group. Impact of asymptomatic COVID-19 patients in global surgical practice during the COVID-19 pandemic. Br J Surg. 2020 Sep;107(10):e364-e365.

5. Al-Jabir A, Kerwan A, Nicola M, Alsafi Z, Khan M, Sohrabi C, O'Neill N, losifidis C, Griffin M, Mathew G, Agha R. Impact of the Coronavirus (COVID-19) pandemic on surgical practice - Part 2 (surgical prioritisation). Int J Surg. 2020 Jul; 79:233-248. 